\title{
Why and wherefore the RSSA?
}

The Radiological Society of South Africa (RSSA) is the professional association of radiologists in South Africa and Namibia. The objectives of the RSSA, as outlined in its constitution, are:

- to define, establish and promote sound relationships among radiologists and between radiologists and hospitals, public and private institutions, government authorities, the international radiological community, radiological groups worldwide, the medical profession in general, and the public

- to promote the common interests of its members

- to promote research in, and advance the science and art of, diagnostic radiology and imaging.

\section{Membership and structure of the RSSA}

There are approximately 400 active members of the society. The majority are ordinary members. The society is proud to have several honourary and life members. There are also categories for affiliated and associated members, including those outside our borders. The RSSA is retained by the Association of Nuclear Physicians to assist with their coding structures and reference price list submissions. The policy-making body of the RSSA is the Council, which is made up of the President (Clive Sperryn), Vice President (Sheldon Godinho), Secretary (Mark Velleman), Treasurer (Ralph Posner), Congress Chairman (Leon Janse van Rensburg) and Member Without Portfolio (Ashesh Ranshod), the immediate Past President (Richard Tuft), the Representative of the Commercial Groupings ( Nigel Flint), the Executive Director (Bates Alheit), the Representative of the University Departments, the Editor of the SA Journal of Radiology (Jan Lotz), the Representatives from the six geographically based branches, and the Chairmen of the various sub-committees and Specialist Interest groups. The Council meets twice a year, to receive report back on the work of the RSSA and to debate and set policy for the way forward. It is incumbent upon the six regional branch representatives to regularly report back to their constituency on the policy direction and work of the RSSA, and to meet with their constituency to garner information for input to Council. The regional branches are North, Central, Free State, KwaZulu-Natal, Eastern Cape and Western Cape.

The Executive Committee consists of the President, Vice President, Secretary, Treasurer, Congress Chairman, the Member Without Portfolio, and representatives of commercial groups, who along with the Executive Director and secretariat, communicate regularly between council meetings to plan and action the work of the RSSA.

\section{The work of the RSSA}

The work of the RSSA is divided into two main streams: education and practice.

The heads of the academic departments co-operate to discuss, maintain and enhance the training of radiologists. Curricula and examinations are co-ordinated to ensure consistent standards of education, and the heads of department interact with the College of Medicine as needed.

The congress chairman runs a busy and world-class continuing professional development (CPD) programme, providing the local radio- logical community with a structured programme of CPD courses and workshops, always with recognised international speakers.

Specialised training courses offered by the equipment suppliers (e.g. CCTA and VC) are run under the auspices of the RSSA.

The RSSA is the custodian of several technology and specialised skills registers which are closely tied in with our academic and specialised training course initiatives. These ensure standardised levels of service delivery and require verified minimum levels of tuition and experience, before registration is granted.

The RSSA works on many other fronts in the practice of radiology in South Africa. With the Department of Health now the custodian of private sector coding and tariff structures, there is ongoing work in the preparation of the annual coding and costing submissions required by the $\mathrm{DoH}$ in recent years.

Daily interaction between the RSSA office and practices and funders takes place regarding billing and tariff queries. The development and introduction of the new radiology tariff structure in 2004 was welcomed by the industry in general, and provides an easy-to-use hierarchical and logical tariff structure.

The RSSA is kept busy with providing legal interpretations and advice on the various current and proposed acts and regulations, and assists members with ethical and legal matters raised at practice level. The RSSA has access to an experienced health care legal team.

The RSSA maintains a website for members and the general public. The content includes structure of committees, coding structures, general news items and specific communications to members. Through our PR consultancy, the RSSA generates regular press releases on current imaging issues for distribution in the lay press.

For the past three years, each October, the RSSA has run successful breast awareness campaigns with the assistance of prominent celebrities, specifically aimed at encouraging breast screening among the broader population. Modality-specific matters are actioned on a needs basis, and usually involve the introduction and gaining of acceptance for new technologies and techniques.

Current, recent and future activities of the RSSA include:

1. Congresses

1.1 International Cancer Imaging Congress - Cape Town, February 2009

1.2 Neuro-imaging Congress - Sandton, August 2009

1.3 Stoller MSK Imaging Workshop - Cape Town, March 2010

2. Coding and tariffs

2.1 Submission to the DoH for 2010 RPL tariffs - April 2009

2.2 Assisting the new specialist private practice forum with a new tariff structure - June 2009

2.3 Regular interaction with funders to benefit design and utilisation matters

2.4 Development of an imaging indications and referral guideline

3. Legal input

3.1 Assistance with interdict of the proposed National Health Insurance Act

3.2 Input in revision of PMBs 